\section{Photodynamic therapy for maculopathy due to radiation retinopathy}

\begin{abstract}
Background/aims To describe the clinical outcomes of four eyes with macular oedema due to radiation retinopathy treated with verteporfin photodynamic therapy (PDT). Methods Interventional Case Series. Four charts of four patients who underwent PDT for macular oedema due to radiation retinopathy were reviewed. Snellen visual acuities, clinical examination and fundus photographs were performed before and after PDT. Main outcome measures were visual acuity, clinical examination before and after PDT.

Results All four eyes had a marked reduction in hard exudates. Three of four eyes had an improvement in vision following the PDT. Conclusion PDT may have a role in the treatment of macular oedema due to radiation retinopathy.

Eye (2005) 19, 795-799. doi:10.1038/sj.eye.6701637; published online 10 September 2004

Keywords: verteporfin; photodynamic therapy; macular oedema; radiation retinopathy; hard exudates
\end{abstract}

\section{Introduction}

Radiation retinopathy may lead to severe visual loss from macular oedema, foveal nonperfusion, retinal ischaemia, retinal detachment, and neovascular glaucoma. ${ }^{1,2}$ Macular oedema was the earliest and most common finding in one study, ${ }^{3}$ occurring within 3 years in $87 \%$ of 218 patients receiving proton beam therapy for paramacular choroidal tumours. Focal laser photocoagulation $^{4,5}$ has been tried in the treatment of radiation-induced macular oedema. In a series of 12 patients $^{4}$ treated with focal laser, median visual acuity improved from

SJ Bakri and PM Beer

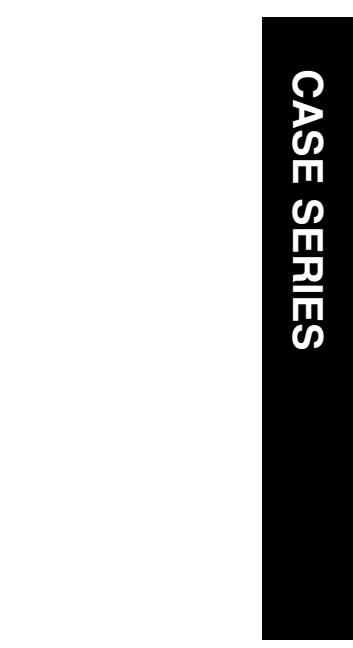

$20 / 100$ preoperatively to $20 / 90$ at the initial postoperative examination (mean follow-up 5 months) and to $20 / 75$ at the final postoperative examination (mean follow-up 39 months). In a chart review of 19 patients, ${ }^{5}$ focal laser treatment was found to modestly improve visual acuity, but no statistically significant difference at 2 years was found. At 6 months, eight of $19(42 \%)$ treated eyes but no observed eyes experienced greater or equal to 1 Snellen line improvement in visual acuity.

One of our patients developed extrafoveal choroidal neovascularization (CNV) after being treated with focal laser for radiation-induced macular oedema. Verteporfin photodynamic therapy (PDT) was used to treat the CNV, rather than ablative laser, in an effort to avoid using the same modality which initially was responsible for causing the $\mathrm{CNV} .{ }^{6}$ We noted, as an incidental finding, that the macular oedema improved with complete resolution of the hard exudates, and visual acuity improved to levels preceding the focal laser treatment. Subsequently, three patients with radiation-induced macular oedema were treated with PDT applied directly to the area of macular oedema, with good results, which we report.

\section{Case reports}

\section{Patient 1}

A 51-year-old white male underwent focal argon laser photocoagulation OD for macular oedema due to radiation retinopathy, with hard exudates threatening the fovea. Four years previously, he had been treated with an Iodine-125 plaque for a choroidal melanoma OD. His visual acuity was 20/20-1 OD but he complained of severe distortion (Figure 1). His left eye was amblyopic. After 2 months, his
Retina Division

Lions Eye Institute Albany Medical College Albany, NY, USA

Correspondence: PM Beer Retina Division Lions Eye Institute Albany Medical College Albany, NY 12208 USA

Tel: + 15182622550

Fax: + 15182622551

E-mail: DrBeer@

RetinaConsultants.org

Received: 15 February 2004 Accepted: 20 April 2004 Published online: 10 September 2004

This paper was presented at the American Society of Retina Specialists Annual Meeting, New York August 20, 2003

The authors have no proprietary interest in any of the products mentioned in this paper. 


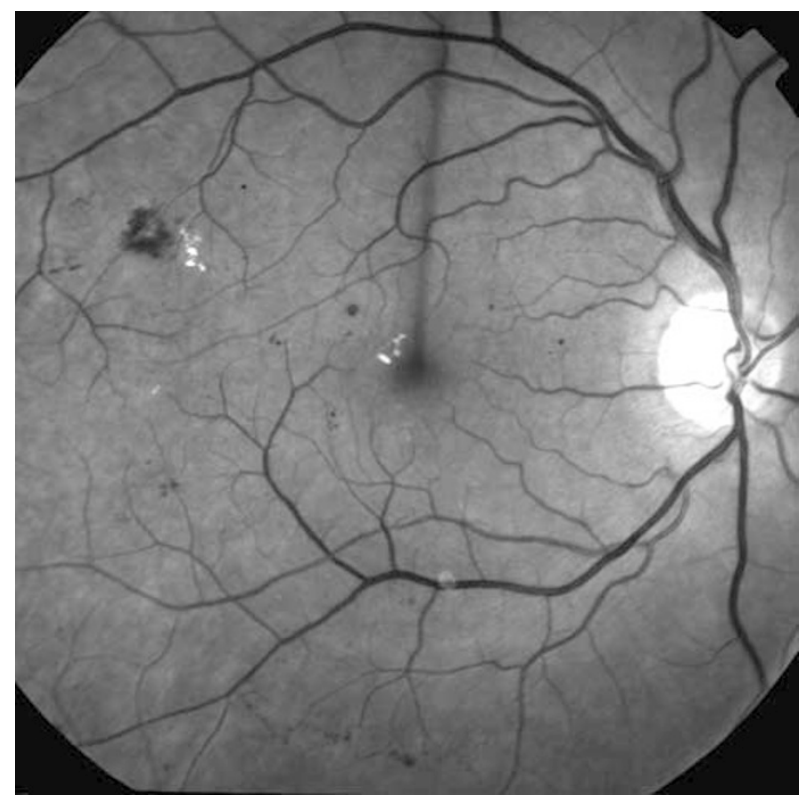

Figure 1 Red free photograph OD shows hard exudates in patient 1 with radiation retinopathy and macular oedema.

visual acuity deteriorated to 20/40 OD with the development of extrafoveal CNV. Treatment options were discussed with the patient, including argon laser photocoagulation and PDT. The patient did not wish to have additional argon laser photocoagulation, as it was the same modality responsible for causing the CNV. His visual acuity OD declined to 20/100 1 month later, when he consented to have PDT. The first treatment was applied over the CNV with a spot size of $1.9 \mathrm{~mm}$, avoiding the fovea. His vision improved to 20/30 OD 1 month later; the distortion, his primary complaint, resolved. The hard exudates caused by the radiation retinopathy and preceding the $\mathrm{CNV}$ also resolved. The patient subsequently underwent two additional sessions of PDT with 3.5 and $5.2 \mathrm{~mm}$ spot sizes, respectively, at 3-month intervals for reperfusion of CNV, this time treating the entire macula. The vision returned to 20/20-2 and the macula was dry clinically (Figure 2). The patient reported that his vision was as good as he could remember prior to the onset of radiation retinopathy. The visual improvement was maintained up to his last visit at 32 months after the first focal laser treatment, the $\mathrm{CNV}$ remained closed, and there was no macular oedema.

\section{Patient 2}

A 43-year-old white female presented with radiation retinopathy after radiation treatment for leukaemia at 18 years of age. Her visual acuity was 20/60 OS and she had macular oedema with accumulation of hard

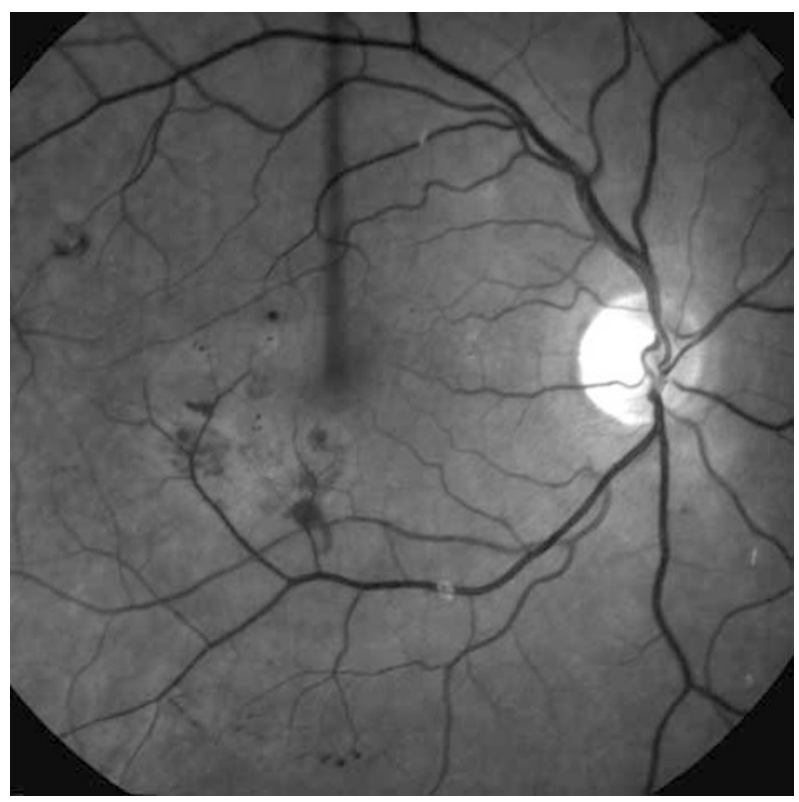

Figure 2 Red free photograph OD shows resolved hard exudates after three sessions of PDT in patient 1.

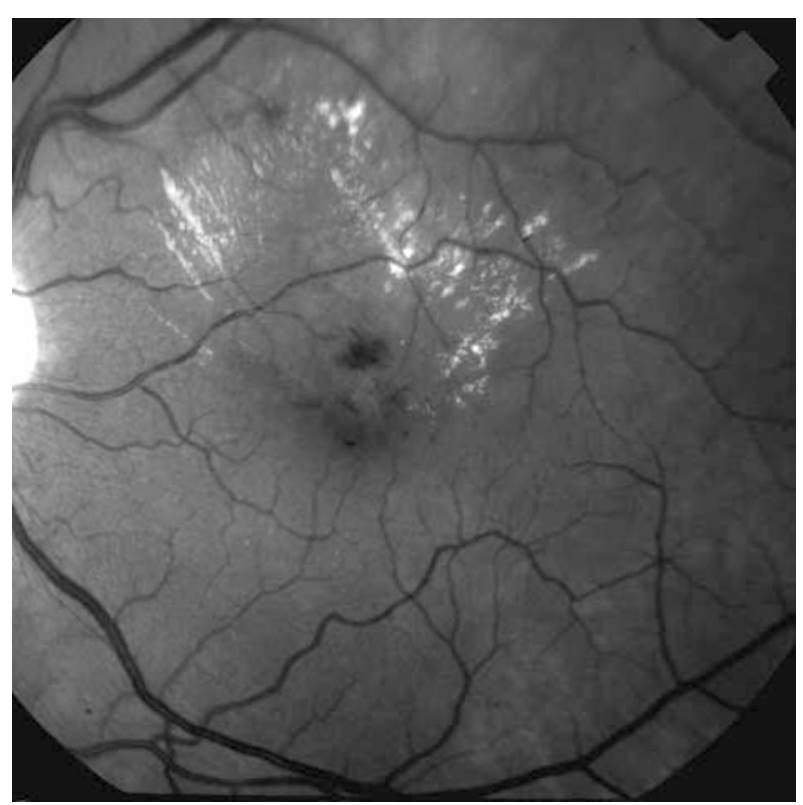

Figure 3 Red free photograph OS shows hard exudates in patient 2 with radiation retinopathy and macular oedema. Visual acuity was $20 / 60$.

exudates (Figure 3). She underwent one session of PDT (one $5.2 \mathrm{~mm}$ spot to the area of leakage sparing the fovea). Vision was 20/60 2 weeks later, 20/40 2 months later, and 20/30 5 months later, with significantly reduced leakage in the macula and a reduction in hard exudates (Figure 4). 


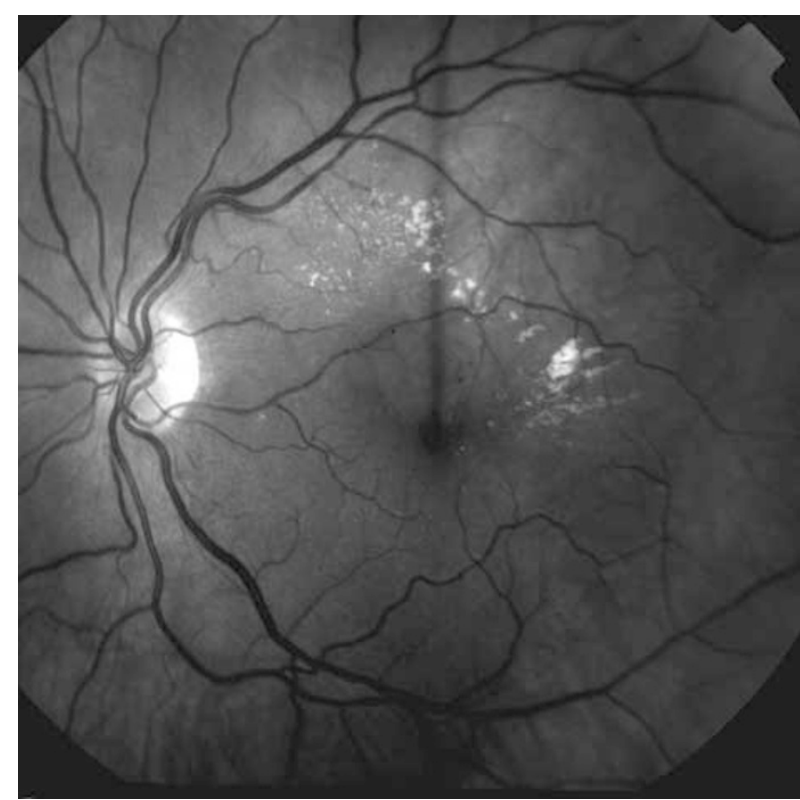

Figure 4 Red free photograph OS shows resolved hard exudates in patient 2 with radiation retinopathy 5 months after one session of PDT. Visual acuity was 20/30.

\section{Patient 3}

A 55-year-old white female had radiation retinopathy OS after treatment of a choroidal melanoma OS with an Iodine- 125 plaque. After the iodine plaque, transpupillary thermotherapy (TTT) was performed to treat the residual tumour. After 4 months, TTT was applied to the tumour again and grid micropulse laser was applied to the macular oedema. At 23 months after the second TTT and macular grid laser, her vision was 20/400, and examination showed macular oedema with accumulation of hard exudates (Figure 5). The patient was then treated with PDT (one spot, $5.2 \mathrm{~mm}$ in size centred on the fovea) and over the next few months she noted a subjective improvement in her vision. After 2 months, the macular thickening had improved clinically and there was a noticeable reduction in hard exudates (Figure 6). Vision was maintained at 20/200 for the next year of follow-up.

\section{Patient 4}

A 73-year-old male had a choroidal melanoma treated by an Iodine 125 plaque and TTT nine years prior in his OS. His vision was reduced to $20 / 400$ secondary to severe macular oedema with accumulation of hard exudates and an exudative macular detachment. He was treated with PDT (one spot $6.9 \mathrm{~mm}$ centred on the fovea). After 3 months his vision has remained the same, the macular thickening persisted, but there was a marked reduction in the amount of hard exudates.

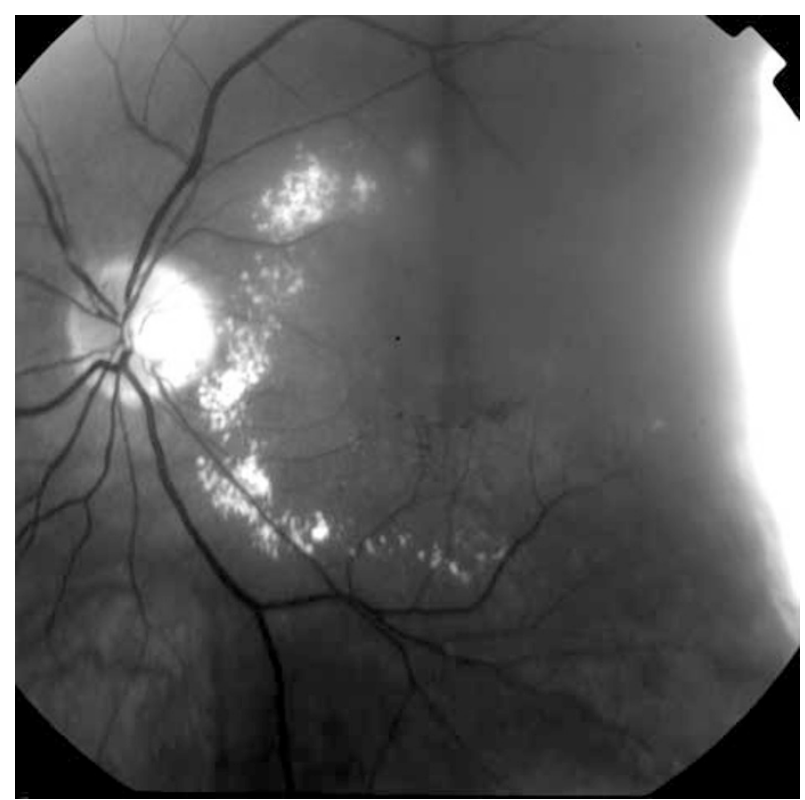

Figure 5 Red free photograph OS shows macular oedema and hard exudates in patient 3 with radiation retinopathy after treatment of a choroidal melanoma OS with an Iodine- 125 plaque. Visual acuity was 20/400.

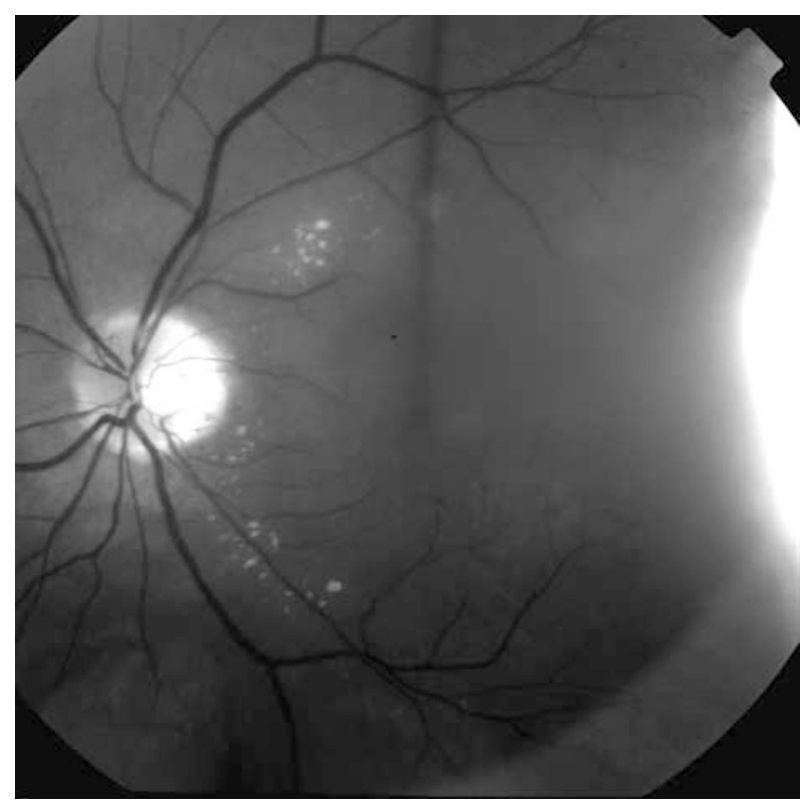

Figure 6 Red free photograph OS shows resolved hard exudates in patient 3, 2 months after one session of PDT. Visual acuity was maintained at 20/200 for the next year of follow-up.

\section{Discussion}

Photodynamic therapy has been used in the treatment of choroidal neovascularization, ${ }^{7-9}$ choroidal

haemangiomas, ${ }^{10}$ and central serous chorioretinopathy. ${ }^{11-13}$ 
It has been shown to be effective in inducing closure of areas of the choriocapillaris, as well as causing focal alterations in the retinal pigment epithelium..$^{14,15}$ The exact mechanism of photodynamic therapy is unclear. It is hypothesized that PDT may be effective in decreasing the state of hyperperfusion in affected areas of the choriocapillaris during the course of central serous chorioretinopathy. It is known that PDT can cause vessel occlusion, and with sufficiently high doses of verteporfin or light administration, retinal vascular occlusions, and attendant visual loss can occur. The treatment regimen adopted for choroidal neovascularization spares normal retinal vessels. The effect of these customary PDT settings on abnormal retinal vessels is not known. We have accidentally discovered that PDT treatment to an iatrogenic $\mathrm{CNV}$ caused an overall decrease in macular exudation in a patient with radiation retinopathy. This therapeutic option was then used to treat three additional patients with macular oedema secondary to radiation retinopathy and found to be equally effective in reducing macular exudation in all patients. Patients 1 and 2 had a marked improvement in vision and the visual improvement appeared to be stable and long lasting. Visual improvement after treatment of CNV with PDT may occur, but is usually transient with a duration of a few weeks. In patients 1 and 2, the visual improvement lasted for the entire duration of follow-up, 32 and 5 months, respectively. Patient 3 had minimal visual improvement, but she had significant foveal ischaemia in addition to severe chronic macular oedema. Patient 4 had an exudative macular detachment and only 3 months of follow-up after his treatment. It is possible that with additional time or additional treatment he could show further benefit.

The mechanism of reduction of macular oedema after grid laser for diffuse macular oedema is not known but there are various hypotheses that all suggest restoration of the blood-retinal barrier. It is possible that selective uptake of verteporfin takes place in damaged retinal vessels, and that the additional injury caused by the photodynamic process induced a reduction of vascular leakage. Alterations in the retinal pigment epithelium ${ }^{14,15}$ as well as concentric retinal pigment epithelial atrophy ${ }^{16}$ have been reported after PDT. It may be that PDT induces changes in the RPE cells, which lead to release of factors which have an effect on the permeability of retinal endothelial cells and restoration of the blood-inner retinal barrier. An insult to the RPE cells may lead to increased oxygen tension at the inner retinal surface due to partial destruction or debridement of RPE cells. These latter two hypotheses have been suggested as possible mechanisms for the reduction of macular oedema after grid laser photocoagulation. However, the target tissue for PDT in this disease model is far from certain. We do not know the mechanism by which our patients had a reduction in macular oedema after PDT, but believe it is an avenue in the treatment of macular oedema which warrants further exploration.

\section{References}

1 Amoaku WM, Archer DB. Fluorescein angiographic features, natural course and treatment of radiation retinopathy. Eye 1990; 4(Part 5): 657-667.

2 Brown GC, Shields JA, Sanborn G, Augsburger JJ, Savino PJ, Schatz NJ. Radiation retinopathy. Ophthalmology 1982; 89(12): 1494-1501.

3 Guyer DR, Mukai S, Egan KM, Seddon JM, Walsh SM, Gragoudas ES. Radiation maculopathy after proton beam irradiation for choroidal melanoma. Ophthalmology 1992; 99(8): 1278-1285.

4 Kinyoun JL, Zamber RW, Lawrence BS, Barlow WE, Arnold AM. Photocoagulation treatment for clinically significant radiation macular oedema. Br J Ophthalmol 1995; 79(2): 144-149.

5 Hykin PG, Shields CL, Shields JA, Arevalo JF. The efficacy of focal laser therapy in radiation-induced macular edema. Ophthalmology 1998; 105(8): 1425-1429.

6 Bakri SJ, Beer PM. Photodynamic therapy with verteporfin for classic choroidal neovascularization secondary to focal laser photocoagulation for radiation retinopathy. Ophthalmic Surg Lasers Imaging 2003; 34(6): 475-477.

7 Treatment of Age-related Macular Degeneration With Photodynamic Therapy (TAP) Study Group. Photodynamic therapy of subfoveal choridal neovascularization in age-related macular degeneration with verteporfin: one-year results of 2 randomized clinical trials-TAP report 1. Arch Ophthalmol 1999; 117: 1329-1345.

8 Treatment of Age-related Macular Degeneration With Photodynamic Therapy (TAP) Study Group. Photodynamic therapy of subfoveal choridal neovascularization in agerelated macular degeneration with verteporfin: two-year results of 2 randomized clinical trials - TAP report 2 . Arch Ophthalmol 2001; 119: 198-207.

9 Verteporfin in Photodynamic Therapy Study Group. Verteporfin therapy of subfoveal choroidal neovascularization in age-related macular degeneration: two-year results of a randomized clinical trial including lesions with occult with no classic choroidal neovascularization - verteporfin in photodynamic report 2. Am J Ophthalmol 2001; 131: 541-560.

10 Porrini G, Giovannini A, Amato G, Ioni A, Pantanetti M. Photodynamic therapy of circumscribed choroidal hemangioma. Ophthalmology 2003; 110(4): 674-680.

11 Battaglia Parodi M, Da Pozzo S, Ravalico G. Photodynamic therapy in chronic central serous chorioretinopathy. Retina 2003; 23(2): 235-237.

12 Yannuzzi LA, Slakter JS, Gross NE, Spaide RF, Costa DL, Huang SJ et al. Indocyanine green angiography-guided photodynamic therapy for treatment of chronic central serous chorioretinopathy: a pilot study. Retina 2003; 23(3): 288-298.

13 Canakis C, Livir-Rallatos C, Panayiotis Z, Livir-Rallatos G, Persidis E, Conway MD et al. Ocular photodynamic therapy for serous macular detachment in the diffuse retinal 
pigment epitheliopathy variant of idiopathic central serous chorioretinopathy. Am J Ophthalmol 2003; 136(4): 750-752.

14 Schlotzer-Schrehardt U, Viestenz A, Naumann GO, Laqua H, Michels S, Schmidt-Erfurth U. Dose-related structural effects of photodynamic therapy on choroidal and retinal structures of human eyes. Graefes Arch Clin Exp Ophthalmol 2002; 240(9): 748-757.
15 Schmidt-Erfurth U, Laqua H, Schlotzer-Schrehard U, Viestenz A, Naumann GO. Histopathological changes following photodynamic therapy in human eyes. Arch Ophthalmol 2002; 120(6): 835-844.

16 Wachtlin J, Behme T, Heimann H, Kellner U, Foerster MH. Concentric retinal pigment epithelium atrophy after a single photodynamic therapy. Graefes Arch Clin Exp Ophthalmol 2003; 241(6): 518-521. 